This item was submitted to Loughborough's Institutional Repository (https://dspace.lboro.ac.uk/) by the author and is made available under the following Creative Commons Licence conditions.

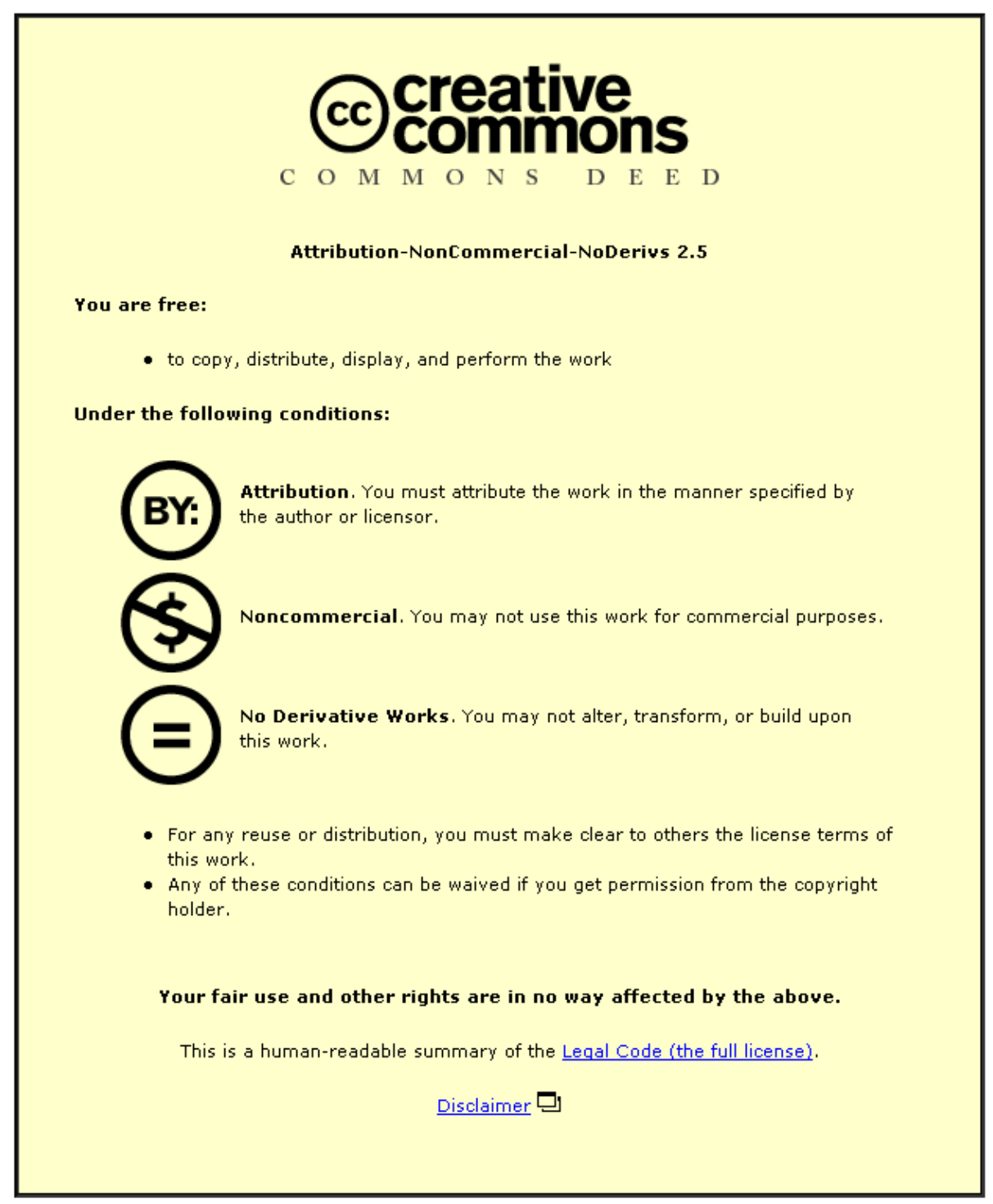

For the full text of this licence, please go to: http://creativecommons.org/licenses/by-nc-nd/2.5/ 


\section{FLEXURAL STRAIN AND CRACK WIDTH MEASUREMENT OF STEEL FIBRE REINFORCED CONCRETE BY OPTICAL GRID AND ELECTRICAL GAUGE METHODS}

Peter Robins, Simon Austin and Peter Jones, Department of Civil and Building

Engineering

Loughborough University, Loughborough, Leicestershire, LE11 3TU, UK

Keywords: crack detection (B), fibre reinforcement $(E)$, fracture toughness $(C)$, image analysis $(B)$, modelling $(E)$

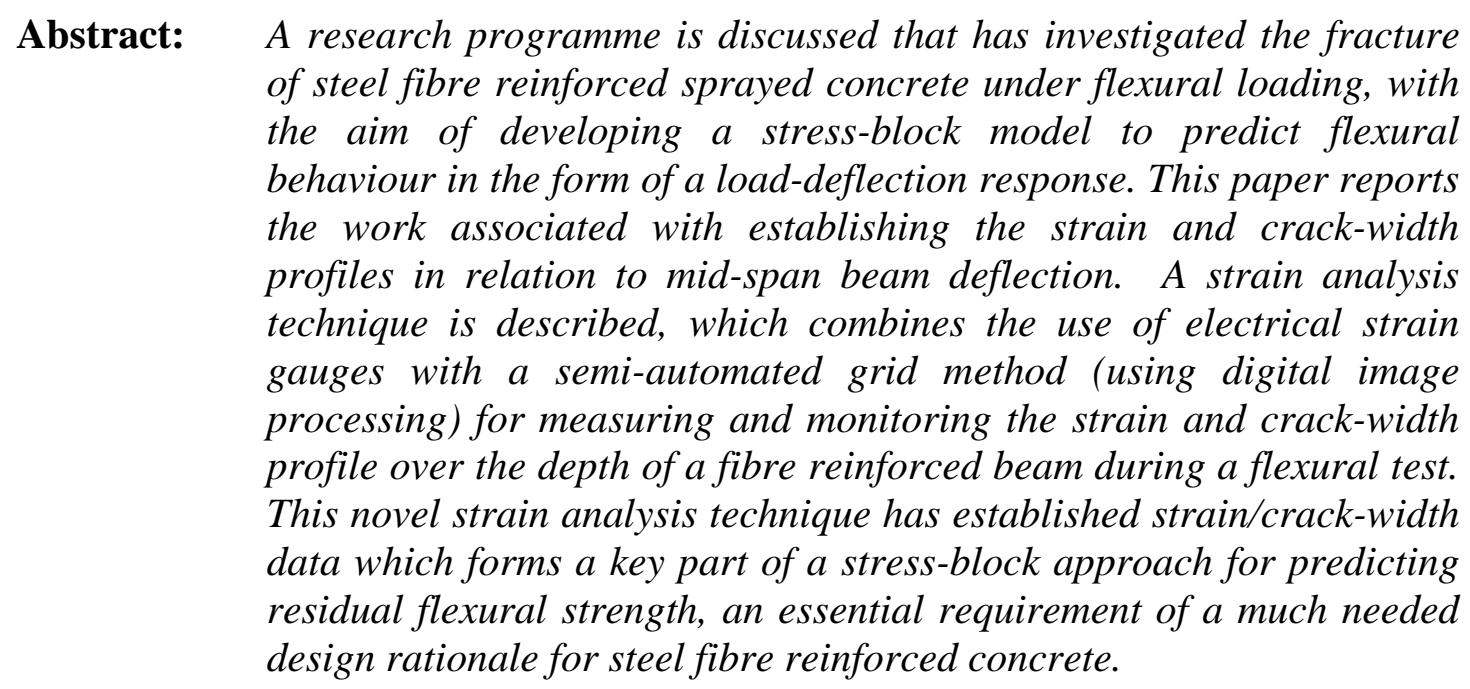

\section{Introduction}

\subsection{Research Objectives}

The work reported here formed part of a larger research project investigating the reinforcing mechanisms and fracture processes associated with steel fibre reinforced sprayed concrete under flexural load. A major aim of this project was to develop a model - based on conventional principles of mechanics - to predict flexural behaviour in the form of a load-deflection response, and thereby predict flexural toughness performance.

The principal objective of this study was to test the following hypothesis: given the matrix compressive strength, fibre volume, fibre type, cross-section dimensions and loading geometry of a steel fibre reinforced sprayed concrete beam, the flexural loaddeflection curve can be predicted using a stress-block diagram approach, if the following principal parameter relationships are known: the uniaxial compressive stress-strain relationship; the uniaxial tensile stress-strain relationship; the single fibre pull-out load versus crack-width relationship; the number, distribution, embedment 
lengths and orientation of the fibres bridging the cracked section of the beam; and the strain profile and the crack-width profile in relation to mid-span beam deflection.

This paper presents work carried out on the last principal parameter listed above, that is the strain and crack-width profiles, whilst that on fibre pullout and distribution are reported elsewhere [1, 2].

\subsection{Flexural modelling}

The proposed model centres on predicting the stress-block diagram at the critical section of a steel fibre reinforced sprayed concrete beam in flexure, for a given midspan deflection. If the shape and magnitude of the stress-block diagram can be ascertained then it can be used to estimate the flexural capacity of the beam in a similar way that stress-block diagrams are used in conventional reinforced concrete design. Thus, flexural loads can be calculated for any given beam deflection and the complete load-deflection response curve can be predicted.

The concept of the model is illustrated in Figs. 1 and 2. A typical load-deflection curve of a steel fibre concrete beam is shown in Fig. 1, where four stages of crack development are indicated: uncracked (stage 1); micro-cracked (stage 2); macro-crack (stage 3); and macro-crack with fibres pulling out (stage 4). The stress block diagram associated with stage 4 is shown in Fig. 2, where the stresses (and resultant forces) that develop at the critical section are represented by three distinct zones: (i) a compression zone; (ii) an uncracked tension zone; and (iii) a cracked tension zone, which is further divided into three sub-zones: an aggregate bridging zone; a fibre bridging zone; and a traction free zone.

A stress-block model requires data relating to a wide range of strain (approximately 200-250 microstrain in tension and 5000 microstrain in compression) and crackwidths up to 5-6mm. The novel strain analysis technique developed for use in this investigation combined electrical resistance strain gauges with a semi-automated grid method using digital image processing.

\section{Research Context}

\subsection{SFRC Sprayed concrete}

Despite continued improvements in materials and spraying technology, the development of steel fibre reinforced sprayed concrete as a preferred construction method for many of the specialist applications that can utilise its flexibility and enhanced toughness performance is hindered by a lack of appropriate analytical design rationales and methods. There is a critical need to develop a fully analytical design procedure, preferably based on conventional principles of mechanics, which is able to predict load-deformation behaviour in flexure for any given member size and loading configuration.

\subsection{Flexural response of SFRC}

A typical load-deflection response obtained from a flexural toughness test, for a steel fibre reinforced concrete beam is shown in Fig. 1. In stage 1, the beam is uncracked and the curve is approximately linear elastic. In stage 2, the matrix tensile strength is reached causing microcracking to develop in the tensile region, resulting in a gradual reduction in the stiffness of the specimen. In a plain beam, microcracking rapidly develops into a macro-crack over the full depth, but in a fibre reinforced beam, the presence of fibres stabilises the cracking process by a variety of toughening 
mechanisms $[3,4]$. Thus restricted microcracking continues until the maximum load is reached, which is thought to coincide with the first macro-crack [5]. In addition, the fibres begin pulling-out from the matrix depending upon the fibre type and volume fraction. During stage 3 the macro-cracks widen and propagate over a greater beam depth causing more fibres to pullout until, during stage 4, fibres begin being completely pulled-out or fractured (causing a traction free zone at the tensile face), eventually leading to the failure of the beam.

Generally, failure occurs at a single crack for fibre contents less than $80 \mathrm{~kg} / \mathrm{m} 3$, multiple cracking being possible at greater fibre contents. In the case of short fibres (i.e. less than $40 \mathrm{~mm}$ in length), a variety of failure patterns may develop depending upon the fibre geometry and volume content [6]. Cracking causes the neutral axis to move towards the compressive face of the beam, so that the equilibrium of the section below the neutral axis is predominantly maintained by the pullout resistance of the fibres bridging the cracks $[7,8]$. In the cracked section the compressive stresses are still related to the composite strains, but the fibres pulling out across the widening crack now provide the tensile forces and hence there is no simple relationship between stress and strain in the cracked region.

Others who have investigated the mechanics of fibre reinforced concrete in flexure have generally assumed that rigid body motion of the two broken halves of specimen, rotating about a 'plastic hinge' located at the neutral axis, to be the dominant failure mode after a specimen in flexure first cracks [9-13]. However, only two of these studies [9, 13] attempted to determine the position of the hinge formed, or its relationship with mid-span deflection. Armelin and Banthia [9] used a semitheoretical basis to show for flexural toughness tests on $100 \times 100 \times 350 \mathrm{~mm}$ beams using third point loading that the neutral axis moves to within $10 \mathrm{~mm}$ of the compressive face of the beam by the time a $1 \mathrm{~mm}$ midpoint deflection has been attained. Mangat and Gurusamy [13] report a similar shift but relate the movement to crack-widths only without any discussion of the associated deflections. Therefore, the question still remains on how to determine and monitor the position of the neutral axis during a flexural test on an FRC specimen.

Assuming that the a cracked FRC beam does rotate about a hinge, then from simple mechanics a relationship should exist between crack mouth opening displacement (CMOD) and mid-span deflection $(\Delta)$. Armelin and Banthia [9] used such an approach (backed up by experimental data) to propose the following linear relationship between these two parameters:

$$
\frac{\Delta}{C M O D}=\frac{l}{4(d-c)}
$$

where $d$ is the depth of the beam, $c$ is the depth of the neutral axis measured from the compressive face of the beam and $l$ is the span (assuming third point loading). Studies by others have also indicated a linear relationship between CMOD and mid-span deflection $[10,12]$.

From extensive experimental investigations involving concrete beams containing 0 $160 \mathrm{~kg} / \mathrm{m}^{3}$ of steel fibres [5, 10, 14-19], the main parameters influencing the shape of the load-deflection curve have been shown to include: fibre volume; fibre type and geometry; specimen size; and matrix composition. Thus the flexural capacity of a steel fibre reinforced concrete beam can be regarded as a function of the following principal parameters: fibre pull-out behaviour; fibre distribution; compressive and tensile stress-strain relationships at the critical section; and the strain distribution and 
crack-width profile with respect to the mid-span deflection of the beam. Work relating to strain and crack width profiles is described below.

\subsection{Strain and crack width measurement}

There are numerous experimental methods available for determining strain distributions and crack-width profiles in flexure [20]. In order to choose the most appropriate for a particular investigation many factors must first be considered for each method, including: (i) the range of strain (or crack-widths) that can be measured; (ii) the accuracy or sensitivity of the measurements obtained; (iii) the maximum specimen size that can be analysed; (iv) whether the method provides a full-field solution or point by point measurements; and (v) whether the method been used in the past for similar work.

\section{Electrical resistance strain gauges}

This is probably the most widely used strain analysis technique. Electrical resistance strain gauges offer a simple, quick and relatively cheap method of strain measurement. The method has been used on numerous occasions in the past for obtaining strain measurements from conventional steel bar and steel fibre reinforced concrete specimens in flexure [21-24]. However, strain gauges only measure strain at the point of fixing and in the direction of the gauge alignment, and therefore they do not provide a full-field analysis. Moreover, the size and geometry of the specimen can limit the number of gauges that can be attached, and strain readings are generally limited to around $2 \%$ strain.

\section{Grid methods}

The grid method is one of the oldest strain analysis techniques available. The method requires the placement of a well defined grid of spots or lines on the surface of the specimen, which is then photographed before and after loading to determine specimen distortion, and hence strains. Early applications of the grid method were limited by three main problems: it was difficult to apply a well defined grid onto the specimen; the analysis was performed manually by eye, and so the accuracy and precision of the results were poor; and the manual analysis of the deformed grid could be very time consuming.

However, with recent advancements in photographic and computer technology, a new automated approach to the grid method has been developed using digital image processing techniques $[25,26]$. In this method, a photo-electronic camera, digitising (A/D) board and a computer based image-processing system are used to capture a digital image of the grid. This digital image is then analysed, using grey-level threshold techniques and centroid algorithms [27], in order to determine the positions of the centroids of the grid spots, and hence the grid deformations and strains.

The main advantages of the automated grid method include: large strains (greater than 5\%) and crack-widths can be measured; the analysis is fully automated; and the method provides a full-field analysis over a large area of the specimen.

The disadvantages are: the method requires expensive state-of-the-art equipment; photo electronic camera technology currently limits the size of the analysed grid to individual areas of approximately $200 \mathrm{~mm}^{2}$; and accuracy can be poor (typically around 500 microstrain). Note also that this method has not been used previously to analyse plain or fibre reinforced concrete specimens in flexure. 


\section{Development of the Optical Grid Method}

\subsection{Background}

The four main stages considered in the development of the optical grid method for strain measurement in the fibre reinforced beams were (i) the application of the grid, (ii) image acquisition, (iii) image processing and (iv) image analysis.

A digital image is an approximation of a real image in which segments of the image are represented by individual digital elements (pixels) in an array of size $\mathrm{X}, \mathrm{Y}$, where $\mathrm{X}$ and $\mathrm{Y}$ are the dimensions of the image in pixels. The light intensity of each element is given by a discrete value termed a 'grey level' in the range $[0, G]$, where level 0 corresponds to zero or minimum light intensity (black) and $G$ corresponds to the maximum light intensity (white). The resolution of a digital image depends on these three parameters (X, Y and $\mathrm{G}$ ), and as their values increase so the approximation of the digital image to the real image improves [26].

The size of the grid spots, and hence the number of pixels making up a spot, is also a limiting factor on the accuracy of an optical grid method. The spacing of the grid spots (or pitch), which essentially equates to gauge length, must also be chosen such that individual grid spots can be easily distinguished. In order to obtain reliable results, Sirkis and Taylor [28] recommend a grid spot diameter of at least 10 pixels and a lower limit on the grid spacing of between 2-3 times the spot diameter. In this investigation these recommendations were achieved by using a grid of $2.5 \mathrm{~mm}$ diameter spots at $5 \mathrm{~mm}$ centres (Fig. 3).

\subsection{Application of the grid}

There are several methods available for applying a black grid of spots onto a white background including stencilling, etching and cementing [25]. Of these stencilling was considered the most versatile and economical for the size and number of specimens to be tested in this investigation. A series of trials were undertaken to assess a variety of stencilling methods: inking using a fine fibre-tipped permanent marker pen; painting using black emulsion; and spraying using a black acrylic primer. The inking method was found to be the most effective as it provided a quick drying application with complete control over the quality of the applied grid spots. As a result this method was adopted in the investigation.

\subsection{Image acquisition}

A photo electronic camera (for example, a charged couple device (CCD) camera) is normally recommended for acquiring a digital image of the grid for strain analysis measurements. This is because of the high degree of accuracy that can be achieved with this type of camera due to the minimal image distortion resulting from the acquired images not being subjected to photographic developing procedures. However, these cameras are very expensive (typically in excess of $£ 10,000$ ), have a limited field of view (approximately $200 \mathrm{~mm}^{2}$ ) and require an on-line analogue-todigital converter.

In this study, an alternative method of digital image acquisition was developed which used a conventional 35mm SLR camera to photograph the grid in combination with proprietary electronic digital scanning technology. This method offers significant advantages over photo electronic image acquisition including relatively low cost, use of readily available equipment, and a virtually unlimited field of view. However, it was also recognised that the accuracy of the method would be compromised by an 
increase in image distortion due to the photographic developing and scanning processes.

A variety of technologies are available for the conversion of the photographic negatives to digital format, and these have recently been reviewed by Chandler and Padfield [29]. At one end of the price/precision range are the high precision systems designed for photogrammetric productions capable of scanning full aerial format imagery at resolutions as low as $7 \mu \mathrm{m}$ with high geometric accuracy. At the other extreme are desktop systems designed for scanning A4 documents at resolutions of $60 \mu \mathrm{m}$ with a consequent degradation of accuracy. However, an alternative in recent scanning technology is the Kodak Photo CD system [29] which has been developed primarily for digitising photographic material for publishing and presenting on a computer.

\subsection{Image processing and analysis}

A digital image processing software package was used to determine the centroid coordinates (in units of pixels) of the grid spots for each of the digital grid images analysed.

Image analysis consists of two main stages: (i) transforming the digital image coordinates, into 'real' two-dimensional photo image co-ordinates in units of millimetres; and (ii) determining grid deformations to enable strain and crack-widths profiles to be computed. A six parameter affine transformation, using least squares, was used to transform the measured pixel co-ordinates system (XY) into the photo coordinate system (xy). This transformation consists of three steps: (i) a correction for size differences by means of scale factors; (ii) a translation to shift the origin of the grid from the $\mathrm{XY}$ digital co-ordinate system to the xy photo system; and (iii) a rotation of the $\mathrm{XY}$ axis to correspond with the xy axis. In order to undertake the transformation the co-ordinates of at least four fixed points have to be known in both the XY digital image co-ordinate system and the xy photo image co-ordinate system. This was achieved by stencilling $20 \mathrm{~mm}$ diameter reference grid spots on to a rigid steel target that was placed on the cross-head of the test machine (Fig. 3).

\section{$4 \quad$ Experimental Details}

\subsection{Materials}

The constituent materials used in the development of the concrete mixes were chosen as being typical of those used in wet process fibre reinforced sprayed concrete. The cement was Class 42.5N Portland Cement (PC) conforming to BS12 [30]. The condensed silica fume was a water-based slurry with a $50 \%$ silica fume content by weight. The aggregate was a $6 \mathrm{~mm}$ maximum sized uncrushed river sand of Zone $\mathrm{M}$ in accordance with BS882 [31], and the aggregate grading generally conformed to the limits of the EFNARC[32] recommended grading curve. A melamine-formaldehyde superplastiser was used, and the steel fibres were $30 \mathrm{~mm}$ long and $0.5 \mathrm{~mm}$ diameter collated hooked-end fibres.

\subsection{Mix proportions and specimen preparation}

The base concrete mix used for the cast beams had a water: cementitious content: aggregate ratio of 0.45:1:2.8 (Table 1). The mix contained a silica fume replacement at $10 \%$ by weight of cement, and steel fibres were added to the base mix in quantities 
of 40,80 and $120 \mathrm{~kg} / \mathrm{m}^{3}$. The average work abilities, 28 day compressive strengths and saturated densities are given in Table 1.

Both notched and unnotched cast beams were used in the investigation. Beam specimens were cast in $100 \times 100 \times 500 \mathrm{~mm}$ steel moulds. Beam depths were either 75 and $100 \mathrm{~mm}$ for the unnotched beams and $60 \mathrm{~mm}$ and $85 \mathrm{~mm}$ for the notched beams. A $10 \mathrm{~mm}$ deep notch was cast into the tensile face of each notched beam at mid-span by attaching a $1 \mathrm{~mm}$ thick brass plate to an appropriately sized timber insert prior to casting. The purpose of the notch was to act as a crack inducer such that the specimens cracked at the notch.

Specimens for flexural toughness testing and strain measurement were also obtained from spraying trials undertaken by an experienced contractor on the site of a wet process steel fibre reinforced concrete project. The same base mix used for the cast mixes (Table 1) was used for spraying, except that the fibre contents produced in-situ were 26 and $66 \mathrm{~kg} / \mathrm{m}^{3}$. Each mix was sprayed by an experienced and certified nozzle operator to produce $600 \times 600 \times 100 \mathrm{~mm}$ test panels. The panels were sealed with a sprayed curing membrane, covered with polyethylene sheeting and stored on-site for approximately 48 hours, before being transported back to the laboratory and demoulded. Each panel was then sawn into three $75 \mathrm{~mm} \times 125 \mathrm{~mm} \times 500 \mathrm{~mm}$ test beams in accordance with EFNARC[32], which were then placed in a curing tank at $20+2^{\circ} \mathrm{C}$ until they were tested.

Specimens were tested in flexure over a span of $450 \mathrm{~mm}$ in third-point loading using a $100 \mathrm{kN}$ capacity floor-mounted Instron 6025 testing machine. Average mid-span beam deflections were measured using an LVDT mounted on a yoke around the specimen to enable net mid-span deflections to be recorded. Tests were performed under closed-loop control of the net mid-span beam deflection. With the notched beams, an additional extensometer was attached across the notch to measure the crack-mouth-opening-displacement (CMOD) during the test. The strain analysis test programme comprised 16 cast and 4 sprayed beams.

\subsection{Optical grid procedure and accuracy}

Four days prior to testing the specimens were taken out of the curing tanks and dried. A grid of $2.5 \mathrm{~mm}$ diameter black spots at $5 \mathrm{~mm}$ centres was then stencilled over the middle-third of one side of each beam. During each test, the specimen grid was photographed at six mid-span deflections: 0, 0.2, 0.5, 1.0, 2.0 and 4.0mm. The test was held at each deflection for 10 seconds to allow the photographs to be taken (Fig. 3). A Cannon T-90 SLR camera equipped with a 50mm lens, and close-up attachment, was used to acquire the $35 \mathrm{~mm}$ photographic negatives of the grid on Kodak Tmax Pro 100 ASA (black and white) film, with a fixed aperture of f/11 and shutter speed of 1/125s. A 0.5 exposure compensation, with centre weighted average metering, enhanced the contrast.

The six photographic negatives obtained from each test were scanned and converted into a digital format using Kodak Photo CD. Digital images were analysed at a resolution of 1024 x1536 with Visilog software to determine the centroid co-ordinates of each grid and reference spot using automatic thresholding techniques. The digital image centroid co-ordinates were then transformed into photo image centroid coordinates and saved in a Microsoft Excel file for subsequent analysis.

Grid deformations were plotted as a function of their location within the grid, and from this plot the position and profile of any crack was determined for each grid image analysed. The accuracy of the grid method was determined by undertaking a 
series of controlled tests under zero strain conditions to establish the smallest grid deformation that could be measured and to determine the effect of camera lens size on the accuracy of the method. The 95\% confidence interval of significant grid deformation was found to be approximately $0 \pm 0.1 \mathrm{~mm}$, irrespective of camera lens size, gauge length or cross-head movement, equating to a strain of approximately $3500 \mu \varepsilon$.

\subsection{Strain gauging}

The electrical resistance gauges were standard single wire strain gauges, with a rigid polyester backing, specifically designed for the measurement of concrete strains. The gauges had a gauge length of $30 \mathrm{~mm}$ and a strain limit of $2 \%$, and were fixed to the concrete using a polyester precoat and a polyester bonding adhesive. The activedummy technique provided temperature compensation.

The strain gauges were fixed at the mid-span section on the opposite side of the beam to the applied grid. A single gauge was installed on the compressive face of each specimen to measure the maximum compressive strain throughout each test, and 4 to 7 (depending on the beam depth) gauges were fixed to the side of the beam at different depths. The accuracy of the strain gauges, determined by comparison with elastic theory, was within $15 \mu \varepsilon$.

\section{$5 \quad$ Strain Profiles and Crack Widths}

\subsection{Crack widths from the grid method}

Representative crack-width profiles for the beams failing at a single crack are shown in Fig. 4 for the four beam sizes investigated, and these results indicate that:

crack-width profiles are linear;

- as the beam deflection increases, the crack widens and its origin moves to within $5 \mathrm{~mm}$ of the compressive face of the beam;

- the CMOD at a given deflection increases with an increase in beam depth for both notched and un-notched beams; and

- crack widths less than $0.2 \mathrm{~mm}$ could not be measured accurately.

Note that in some of the beams the crack occurred outside the area of the grid, and in others multiple cracking occurred. For both cases crack width analysis was not carried out.

As expected the notched beams generally cracked at mid-span (i.e. at the notch ) but the unnotched beams did not. Fig. 5 shows the variation in CMOD (obtained from the crack-width profiles) as a function of the distance the crack occurred from mid-span for the 75 and 100mm deep unnotched beams. The results show a general increase in the value of CMOD for an increase in the distance the crack occurred from mid-span.

This may provide an explanation for the high variability commonly observed in flexural toughness testing [9]. For an unnotched beam tested in third-point loading, the failure crack can occur anywhere within the middle third without the test being invalidated. For a beam not cracking at mid-span, the 'true' deflection of the beam at the crack will be greater than the deflection at mid-span, and as a result of the increase in beam deflection at the crack (relative to the beam deflection at mid-span) the CMOD will be greater at the crack (Fig. 5). In the case of notched beam tests, these influencing factors are minimised because the crack occurs at the notch (i.e. mid span) and hence the variability in the load-deflection responses will be reduced. Notched 
beams, therefore, appear to offer an advantage for flexural toughness tests controlled by mid-span deflection.

Validation of the crack width measurements obtained from the grid method is demonstrated in Fig. 6, which compares the crack-width profiles obtained from the grid method (Fig. 4(b)) with average CMODs measured using an extensometer fixed at the notch. Note that the crack profiles in Fig. 6 have been extrapolated to the point at which CMOD was measured during the flexural toughness tests (that is, at a distance of $95 \mathrm{~mm}$ from the compressive face of the beam). Good agreement between the results can be seen.

The relationships shown in Figs. 4 and 7 appear to indicate the following results: (i) a cracked FRC beam is subjected to rigid body motion rotating about a central hinge; (ii) CMOD is linearly related to mid-span deflection; and (iii) CMOD at a given deflection increases with increasing beam depth. These results agree well with previous work [9, 12] as discussed earlier. In particular, the results provide a reasonable fit with the relationship proposed by Armelin and Banthia [9] - equation 1 - between CMOD and mid-span deflection. Assuming that the neutral axis is located at a distance from the compressive face corresponding to approximately $5 \%$ of the beam depth at a deflection of $4 \mathrm{~mm}$ (see Fig. 10), comparisons can be made between the theoretical and experimental data using equation 1 . For the beam sizes used in this study this gives theoretical deflection/CMOD ratios at a deflection of $4 \mathrm{~mm}$ of 1.18 , 1.58 and 2.37 for the beam depths of $100 \mathrm{~mm}, 75 \mathrm{~mm}$ and $50 \mathrm{~mm}$ respectively, which compare favourably with the corresponding experimental ratios (Fig. 7) for the three beam sizes of $1.20,1.43$ and 2.45 .

\subsection{Strain profiles from the gauges}

Unlike the grid method which is able to measure the crack-widths across the cracked section of a beam, providing that that the beam cracks within the area of the grid, the strain gauges measure strain at fixed points located at the mid-span section irrespective of the crack position. Therefore, only if a beam cracks at mid-span will the gauges yield information on the distribution of strain at a cracked section in a beam. Fig. 8 shows strains in a beam that cracked at mid-span. Note the magnitude of the strain gradient, and the fact the gauges recorded tensile strains of 3500 to over $7000 \mu \varepsilon$ before gauge failure occurred (characterised by a sudden drop in the gauge reading). These high values are not of course tensile strains in the concrete, but are an indication of the crack width.

The influence of the proximity of the crack, relative to the centre of gauges, on the profile of the strains recorded is further illustrated in Fig. 9, which shows how the neutral axis depth (relative to the compressive face of the beam) changes with distance from the crack. Prior to the beam cracking (i.e. at deflections up to approximately $0.15 \mathrm{~mm}$ ) the neutral axis is located at mid-depth across the whole of the middle third region of the beam. Following cracking there is a shift in the neutral axis position towards the compressive face of the beam; the magnitude of this shift decreases with increasing distance from the crack. For example, at a deflection of $2 \mathrm{~mm}$ the neutral axis depth is within $10 \mathrm{~mm}$ of the compressive face of the beam at the crack, but close to mid-depth at a distance of $75 \mathrm{~mm}$ from the crack. These results are similar to the movement in the neutral axis position as reported by Armelin and Banthia [9] and Mangat and Gurusamy [13] following semi-theoretical studies of FRC beams in flexure. 
The strain readings obtained from all the tests were combined and extrapolated to determine an average strain profile (at each deflection) for a crack occurring at midspan. The average strain profiles were then used to determine a neutral axis depth and maximum compressive strain. Figs. 10(a) and 10(b) show the relationship between these parameters for the $60 \mathrm{~mm}$ notched, the $85 \mathrm{~mm}$ notched, and the $100 \mathrm{~mm}$ unnotched beams. Note that in these figures neutral axis depth is plotted as fraction of the corresponding overall beam depth, $d$.

The relationships of Fig. 10 suggest that the shape of the strain profile of a fibre reinforced concrete beam, with a relatively low fibre content, may be independent of beam depth. More specifically, for the range of beam depths and fibre contents investigated, the average strain profiles reflect the following behaviour:

(i) once the beam cracks the neutral axis moves rapidly towards the compressive face of the beam, with the rate of movement gradually reducing with increasing deflection, Fig. 10(a);

(ii) the maximum compressive strain increases non-linearly with an increase in deflection (Fig. 10(b)) and corresponding movement in the neutral axis position towards the compressive face of the beam; and

(iii) over the deflection range investigated, the value of maximum compressive strain never exceeded $3200 \mu \varepsilon$, indicating that no beams failed in compression.

\subsection{Complete profile from combination of data}

The final stage of the strain analysis investigation was to combine the crack-width profiles obtained from the grid method with the strain profiles obtained from the strain gauge analysis, in order to determine the complete strain/crack-width profiles for use in the proposed model. The interface between the strain and crack-width profiles was assumed to occur at the point along the strain profile where the matrix cracking strain is first exceeded, corresponding to a zero-crack-width (Fig. 11). The depth of this point, relative to the compressive face of the beam, is termed the 'zero crack-width depth'. In this analysis the concrete matrix cracking strain was assumed to be $190 \mu \varepsilon$, this being the average cracking strain from the tests (range 165 to 225 $\mu \varepsilon)$.

The strain gauges were found to be suitable for measuring both the compressive and tensile strain profiles to an accuracy of $\pm 15 \mu \varepsilon$ up to a strain limit of around $200 \mu \varepsilon$ in tension and $3500 \mu \varepsilon$ in compression, and the grid method was found to be suitable for measuring crack-widths greater than $0.2 \mathrm{~mm}$ to an accuracy of $\pm 0.1 \mathrm{~mm}$. Thus, when using a combination of these methods, it seems that a range of specimen deformation exists - between a strain of $200 \mu \varepsilon$ (equivalent to $0.006 \mathrm{~mm}$ over a gauge length of $30 \mathrm{~mm}$ ) and a crack-width of $0.2 \mathrm{~mm}$ (equivalent to $6500 \mu \varepsilon$ over a gauge length of $30 \mathrm{~mm}$ ) - which cannot be accurately measured. However, it was found that when a crack passed under an electrical strain gauge, without failure of the gauge, the output of the gauge could be converted to a crack width (by assuming that once the crack has formed all the deformation recorded by the gauge is the crack opening). In this manner the gauges were found to give information on crack widths in the range 0 to about $0.1 \mathrm{~mm}$.

The combination of strain gauging and the grid method can therefore yield information on compressive strains (from gauges), tensile strains before cracking (from gauges), and crack widths (0 to $0.1 \mathrm{~mm}$ from gauges, and $0.2 \mathrm{~mm}$ upwards from grid readings). Examples of combined strain and crack width profiles are shown in Fig. 12 for one of the $75 \mathrm{~mm}$ deep beams at mid-span deflections of $0.5 \mathrm{~mm}$ and 
$1.0 \mathrm{~mm}$. Note that at the $0.5 \mathrm{~mm}$ deflection, most of the crack width information has come from the gauges, whereas for the $1 \mathrm{~mm}$ deflection most has come from the grid method. The information from the grid measurements and the electrical strain gauges can be seen to complement each other, providing information on strains and crackwidths over the full depth of the section.

\section{Conclusions}

A strain analysis technique has been developed, which combines electrical strain gauges with a semi-automated grid method (using digital image processing) for measuring and monitoring the strain and crack-width profile over the depth of a fibre reinforced beam during a flexural test. The main merit of this technique is its ability to measure a wide range of full-field strain and crack-widths using these two relatively simple techniques of strain measurement.

The technique has been shown to be capable of measuring strain to an accuracy of $\pm 15 \mu \varepsilon$ over a range between $200 \mu \varepsilon$ in tension and $3500 \mu \varepsilon$ in compression, and crackwidths greater than $0.2 \mathrm{~mm}$ to an accuracy of $\pm 0.1 \mathrm{~mm}$ form the grid method with the possibility of crack width information from the strain gauges in the crack width range 0 to $0.1 \mathrm{~mm}$.

The strain profile results show that fibre reinforced concrete beams, with a given test geometry and fibre content, have a common failure mode in terms of the movement in the neutral axis position (measured as a fraction of beam depth) and the associated values of maximum compressive strain measured at the compressive face of the beam, which appears to be independent of beam depth.

The crack-width profile results show that, for a given deflection, the width of a propagating crack increases linearly over the depth of a beam. In terms of the crackmouth-opening-displacement (CMOD), the results show that: (i) the CMOD increases linearly with increasing mid-span deflection, and (ii) the CMOD at a given deflection increases with an increase in beam depth.

An essential element of the stress block approach to predicting the flexural behaviour of steel fibre reinforced concrete has been established.

\section{Acknowledgements}

The authors are grateful to Gunform Ltd for their assistance with the sprayed field trials.

\section{References}

[1] P.J. Robins, S.A. Austin and P.A. Jones, Pull-out behaviour of steel fibres, submitted to Cement and Concrete Research (1999).

[2] P.J. Robins, S.A. Austin and P.A. Jones, Spatial distribution of steel fibres affecting flexure of sprayed and cast concrete beams, in preparation, (1999).

[3] V.C. Li and M. Maalej, Toughening in cement based composites, Part I: Cement, mortar and concrete, Cement \& Concrete Composites 18 (1996) 223-237.

[4] V.C. Li and M. Maalej, Toughening in cement based composites, Part II: Fiber reinforced cementitious composites, Cement \& Concrete Composites 18 (1996) 239-249. 
[5] P.N. Balaguru and S.P. Shah, Fiber-Reinforced Cement Composites, McGraw-Hill, New York, 1992.

[6] G.B. Batson, Review of the state-of-the-art of steel fibre reinforced concrete, Proceedings of the Workshop on Fibre Reinforced Cement and Concrete, National Science Foundation (USA), Sheffield, July (1994) 88-106.

[7] D.J. Hannant, Fibre Cements and Fibre Composites, J. Wiley \& Sons Ltd., Chichester, England, 1978.

[8] N. Banthia, A study of some factors affecting the fibre-matrix bond in steel fiber reinforced concrete, Canadian Journal of Civil Engineering 17 (1990) 610-620.

[9] H.S. Armelin and N. Banthia, Predicting the flexural postcracking performance of steel fiber reinforced concrete from the pullout of single fibres, ACI Materials Journal 94 (1) (1997) 18-31.

[10] V.S. Gopalaratnam, S.P. Shah, G.B. Batson, M.E. Criswell, V. Ramakrishnan and M. Wecharatana, Fracture toughness of fiber reinforced concrete, ACI Materials Journal 88 (4) (1991) 339-353.

[11] T.Y. Lim, P. Paramasivam, and S.L. Lee, Bending behaviour of steel-fiber concrete beams, ACI Structural Journal, 84 Nov-Dec (1987) 524-536.

[12] D. Jamet, R. Gettu, V.S. Gopalaratnam, and A. Aguado, Toughness of fiber-reinforced highstrength concrete from notched beams, Testing of Fiber Reinforced Concrete, SP 155-2, ACI, Detroit (1995) 23-39.

[13] P.S. Mangat and K. Gurusamy, Flexural strength of steel fibre-reinforced cement composites, Journal of Materials Science, 22 (1987) 3103-3110.

[14] N. Banthia and J.F. Trottier, Concrete reinforced with deformed steel fibres Part II: Toughness characterisation, ACI Materials Journal 92 (2) (1995) 146-154.

[15] V. Ramakrishnan, S.S. Yalamanchi and S. Kakodkar, Parameters influencing the flexural toughness of steel fibre reinforced concrete, National Science Foundation (USA), Proc. of Workshop on Fibre Reinforced Cement and Concrete, Sheffield, July (1994) 181-193.

[16] P. Balaguru, R. Narahari and M. Patel, Flexural Toughness of Steel Fiber Reinforced Concrete, ACI Materials Journal 89 (6) (1992) 541-546.

[17] P. Soruoshian and Z. Bayasi, Fiber-type effects on the performance of steel fiber reinforced concrete, ACI Materials Journal 88 (2) (1991) 129-134.

[18] R.J. Ward and V.C. Li, Dependence of flexural behaviour of fiber reinforced mortar on material fracture resistance and beam size, ACI Materials Journal 87 (6) (1990) 627-637.

[19] V.S. Gopalaratnam and S.P. Shah, Strength, deformation and fracture toughness of fibre cement composites at different rates of flexural loading, Steel Fibre Concrete, eds. S.P. Shah and A. Skarendahl, Swedish Cement and Concrete Research Institute, Stockholm (1985) 229-331.

[20] J.W. Dally and W.F. Riley, Experimental Stress Analysis, $3^{\text {rd }}$ edition, McGraw-Hill Inc., Singapore, 1991. 
[21] J.A. Purkiss and P.B. Blagojevic, Comparison between the short and long term behaviour of fibre reinforced and Un-reinforced Concrete Beams, Composite Structures 25 (1993) 45-49.

[22] R. Babut and A.M. Brandt, The Method of Testing and Analysing of Steel Fibre Reinforced Concrete Elements in Flexure, Proceedings of the RILEM Symposium, edited by R.N. Swarmy, The Construction Press, Lancaster, England (1978) 479-486.

[23] V.S. Gopalaratnam and S.P. Shah, Softening response of plain concrete in direct tension, ACI Journal 82, May-June (1985) 310-323.

[24] G.M. Sturman, S.P. Shah and G. Winter, Effects of flexural strain gradients on microcracking and stress-strain behaviour of concrete, ACI Journal, July (1965) 805-821.

[25] P.J. Sevenhuijsen, The photonical, pure grid method, Optics and Lasers in Engineering 18 (1993) 173-194.

[26] R.C. Gonzalez and R.E. Woods, Digital Image Processing, Addison-Wesley Publishing, London, 1992.

[27] R.W. Fail and C.E. Taylor, An application of pattern mapping to plant motion, Experimental Mechanics, December (1990) 404-410.

[28] J.S. Sirkis and C.E. Taylor, Displacement pattern matching and boundary-element methods for elastic-plastic stress analysis, Experimental Mechanics, March (1990) 26-33.

[29] J.H. Chandler and C.J. Padfield, Automated Digital Photogrammetry on a Shoestring, Photogrammetry Record, 15(88) (1996) 545-559.

[30] BS 12, Specification for Portland Cements, British Standards Institution, Milton Keynes, 1991.

[31] BS 882, Aggregates from Natural Sources for Concrete, British Standards Institution, Milton Keynes, 1992.

[32] EFNARC, European Specification for Sprayed Concrete, European Federation of National Association of Specialist Repair Contractors and Material Suppliers for the Construction Industry, Aldershot, UK, 1996. 


\begin{tabular}{|l|c|}
\hline Constituents & \\
\hline Cement $\left(\mathrm{kg} / \mathrm{m}^{3}\right)$ & 490 \\
Silica Fume $\left(\mathrm{kg} / \mathrm{m}^{3}\right)$ & 50 \\
Water $\left(\mathrm{kg} / \mathrm{m}^{3}\right)$ & 245 \\
Aggregate $\left(\mathrm{kg} / \mathrm{m}^{3}\right)$ & 1510 \\
Superplasticiser (\% by weight of & 1.5 \\
cementitious material) & $0,40,80$ \& \\
Steel Fibres (kg/m $\left.{ }^{3}\right)$ & 120 \\
\hline Properties * & $55-90$ \\
\hline Slump (mm) & $72-74$ \\
Compressive strength (MPa) & $2230-2300$ \\
Density (kg/m $\left.{ }^{3}\right)$ & \\
\hline
\end{tabular}

* range of average values of the mixes with $0-120 \mathrm{~kg} / \mathrm{m}^{3}$ steel fibres

Table 1 Mix proportions and basic properties

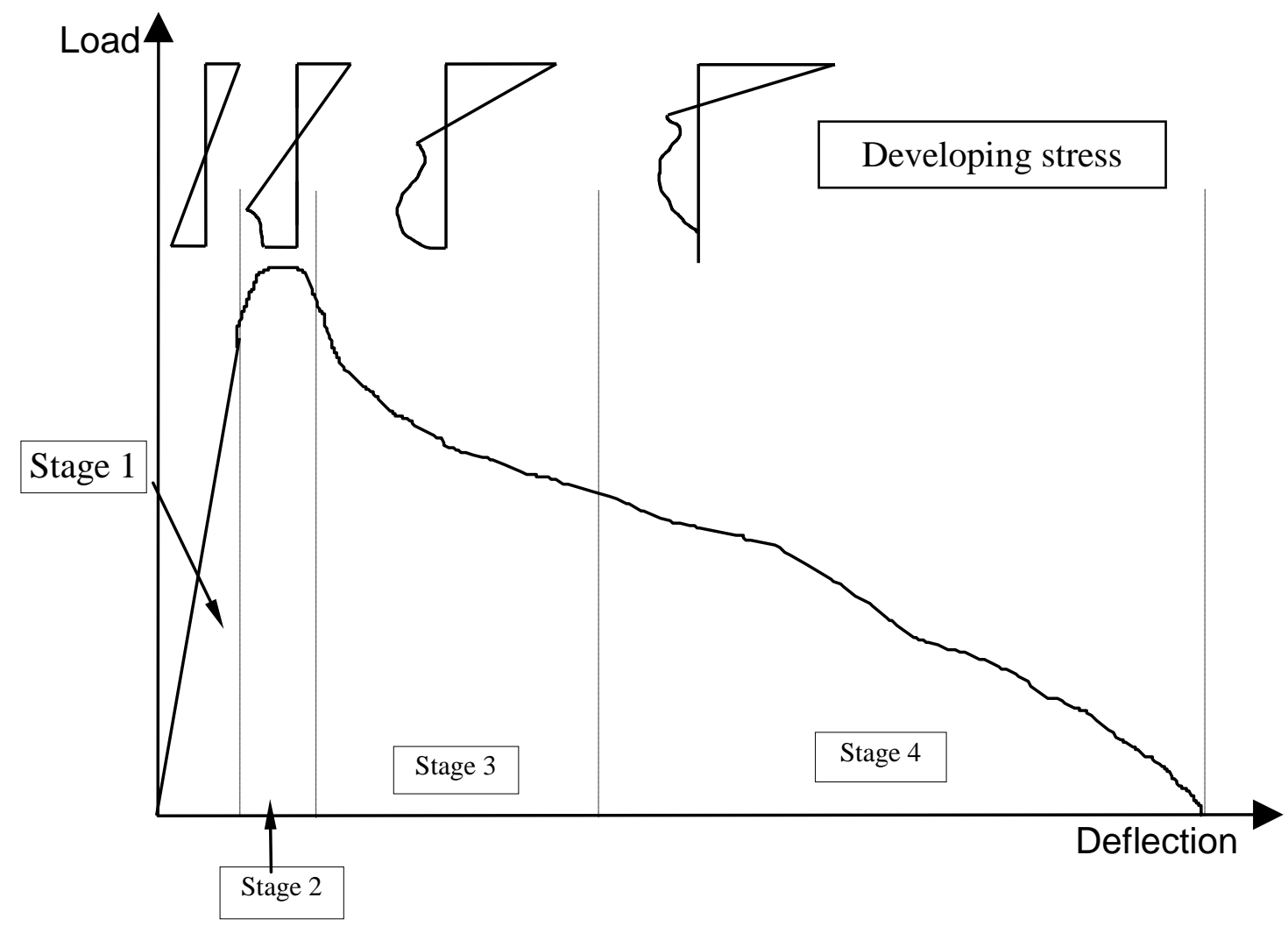

Figure 1 Relationship between the four stages of crack-propagation and the flexural load deflection response of a steel fibre reinforced concrete beam 


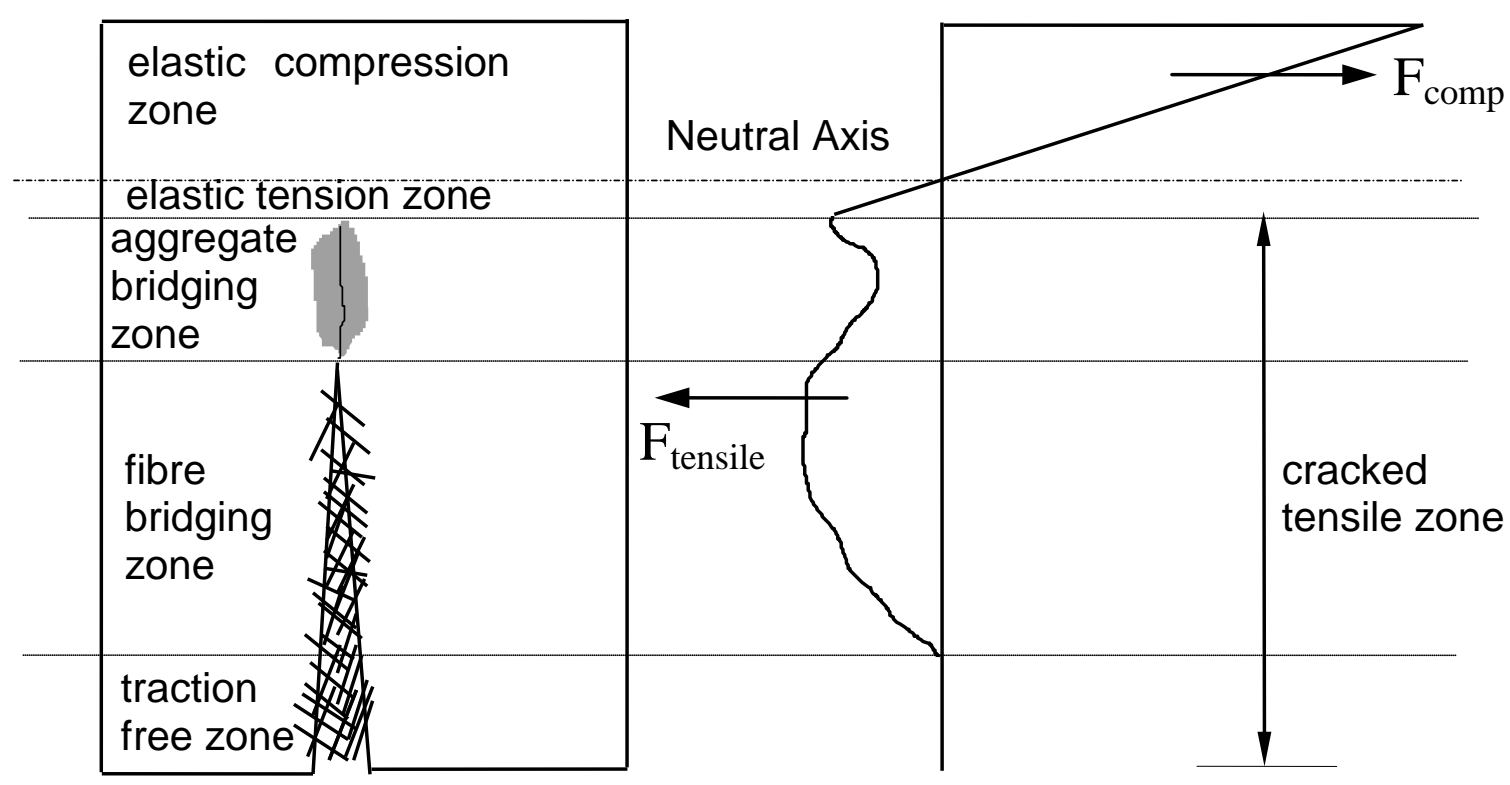

Figure 2 Schematic representation of a steel fibre reinforced concrete beam under flexural loading: Stage 4 - development of traction free zone 


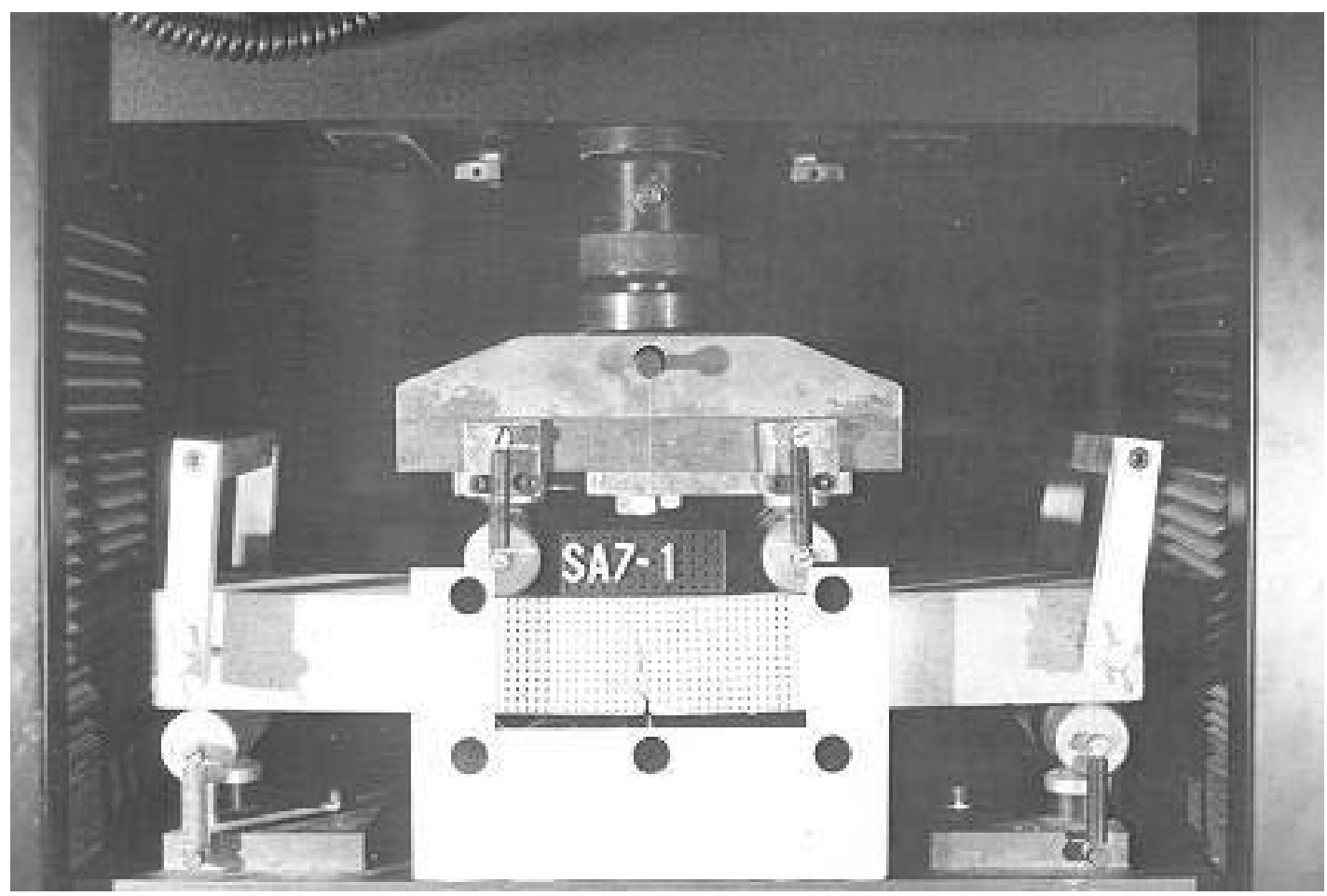

FIGURE 3 GRID METHOD TEST SPECIMEN AND TARGET 


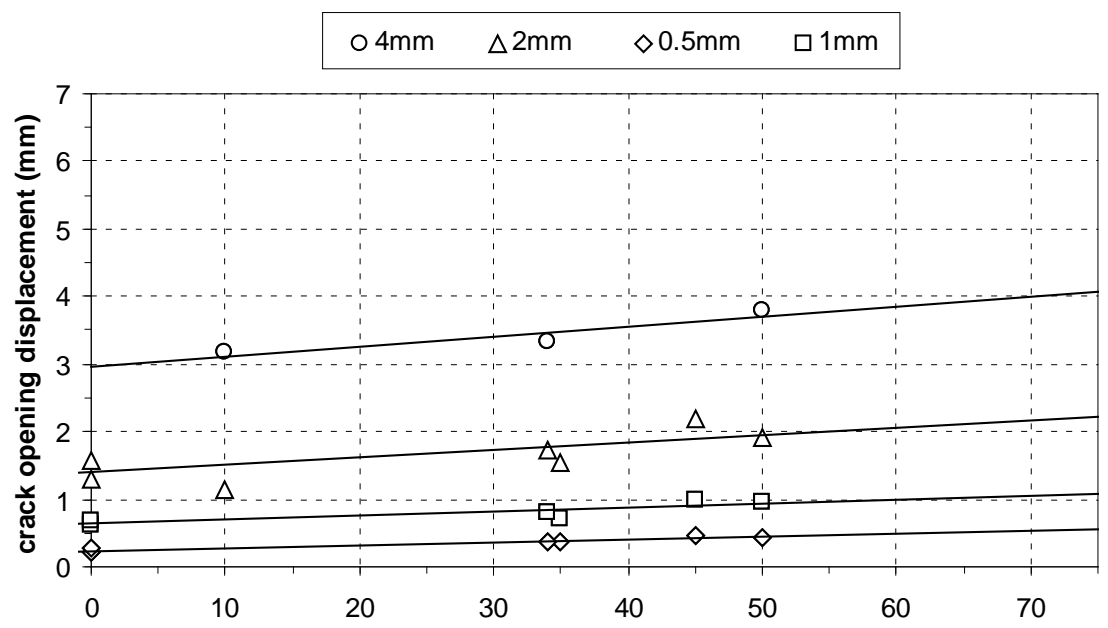

(a) $75 \mathrm{~mm}$ unnotched specimens.

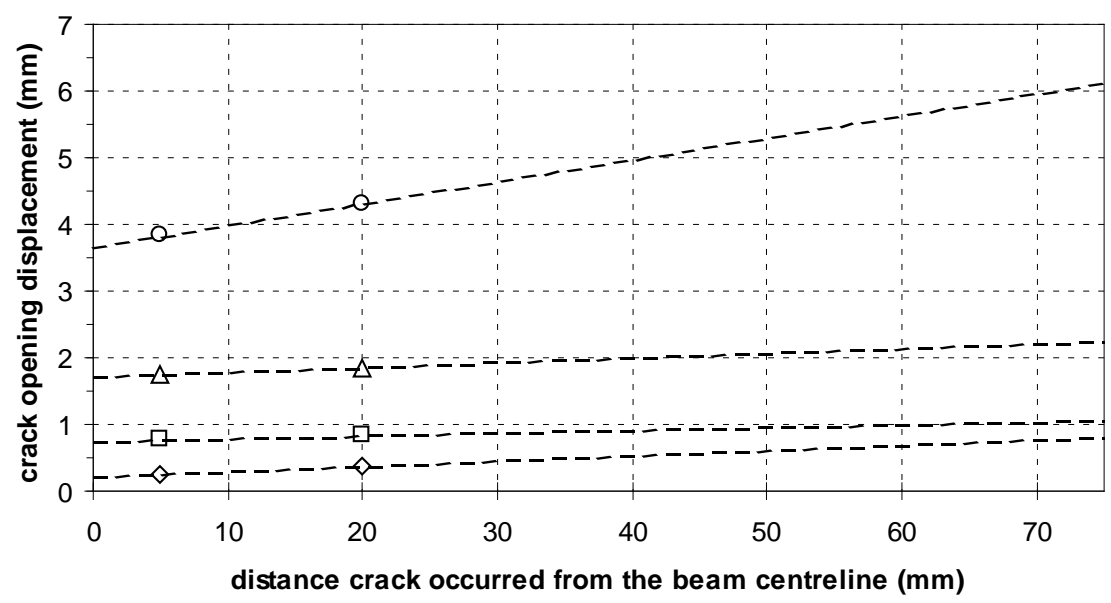

(b) $100 \mathrm{~mm}$ unnotched specimens.

Figure $5 \quad$ Variation in CMOD with distance crack occurred from mid-span 


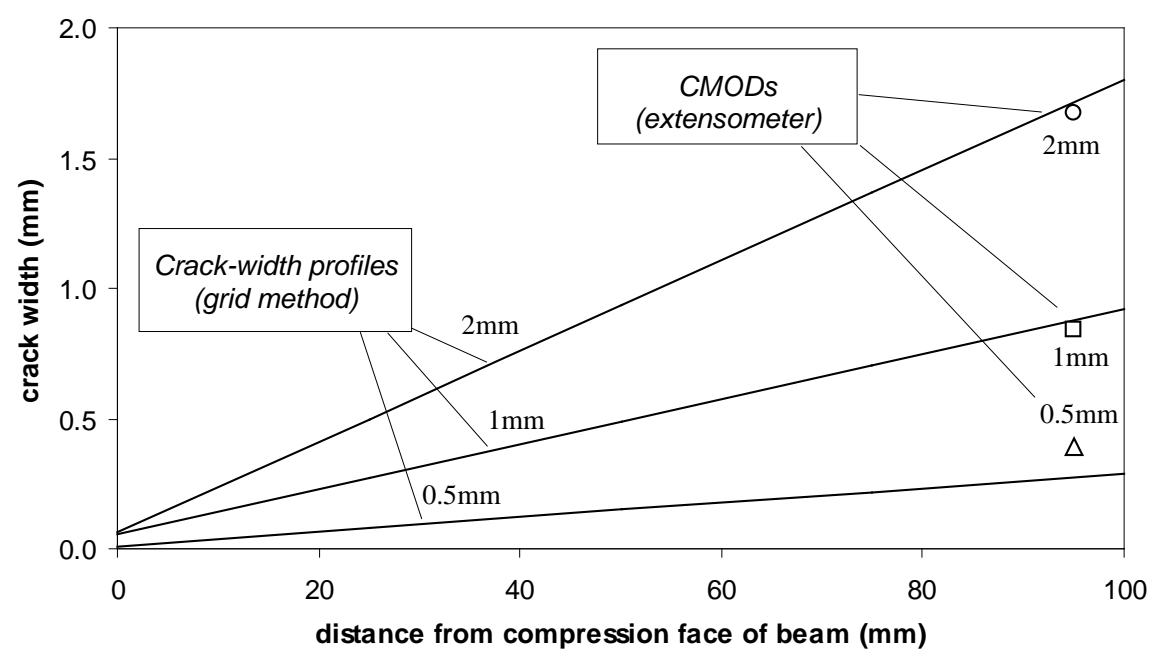

Figure $6 \quad$ Comparison of grid method crack-width profiles with CMOD values from extensometer at the notch for varying midspan deflections $(85 \mathrm{~mm}$ deep notched beam)

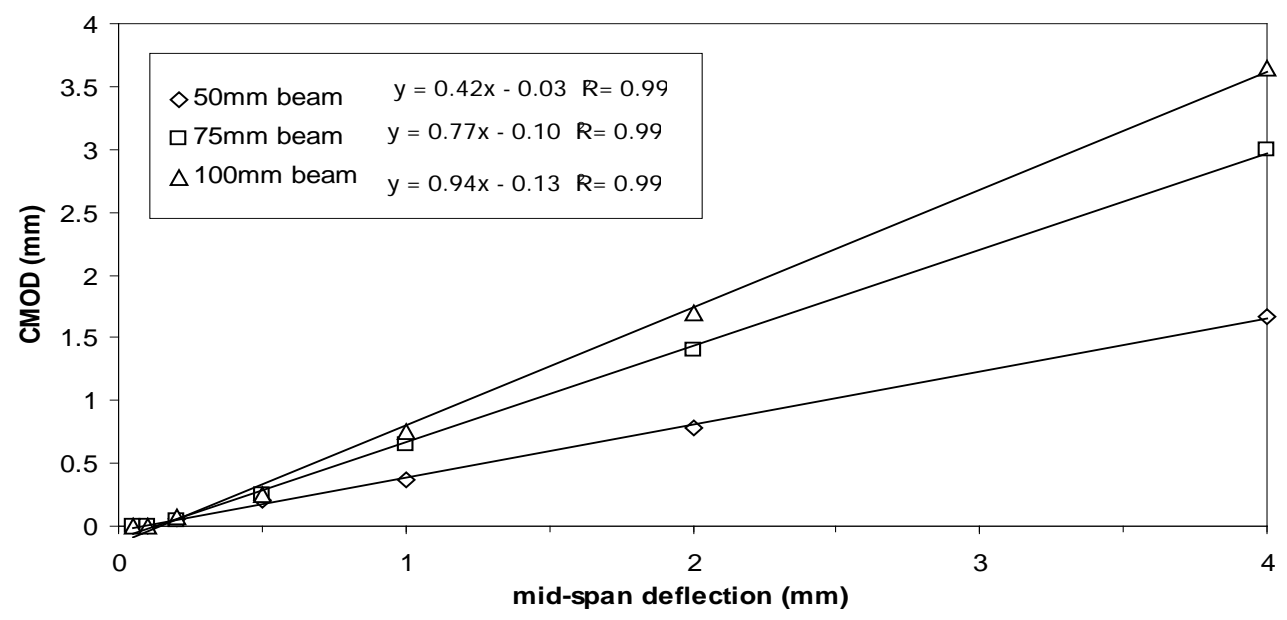

Figure $7 \quad$ Relationship between CMOD and mid-span deflection 


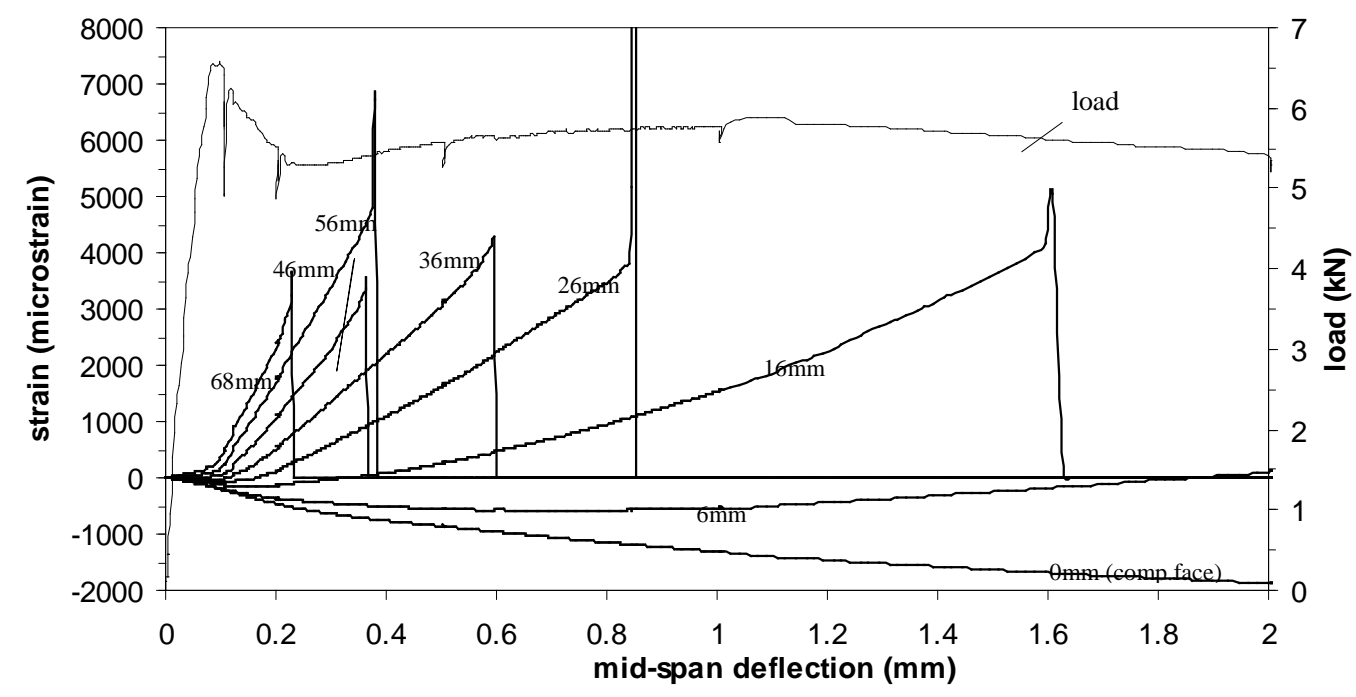

Figure 8 Influence of strain gauge reading relative to compression face of a $85 \mathrm{~mm}$ deep notched beam - crack occurring close to mid-span (compressive strain negative) 


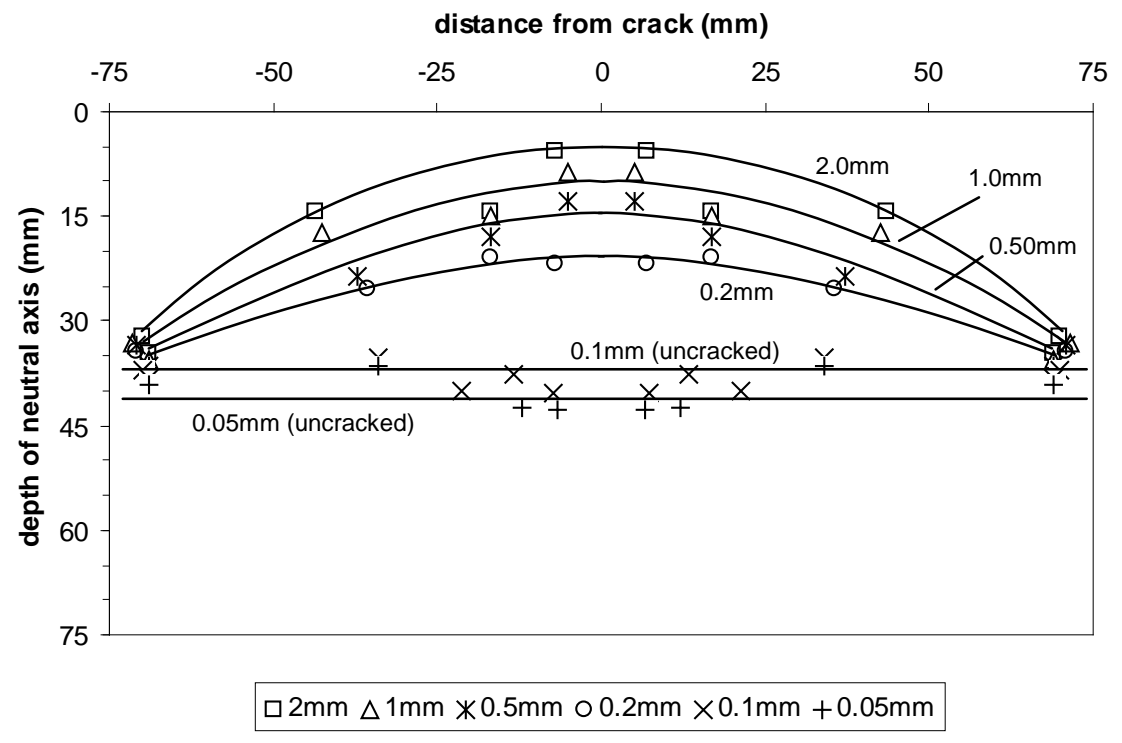

Figure 9 Distribution of neutral depth either side of a crack (75mm unnotched and $85 \mathrm{~mm}$ notched beams) 

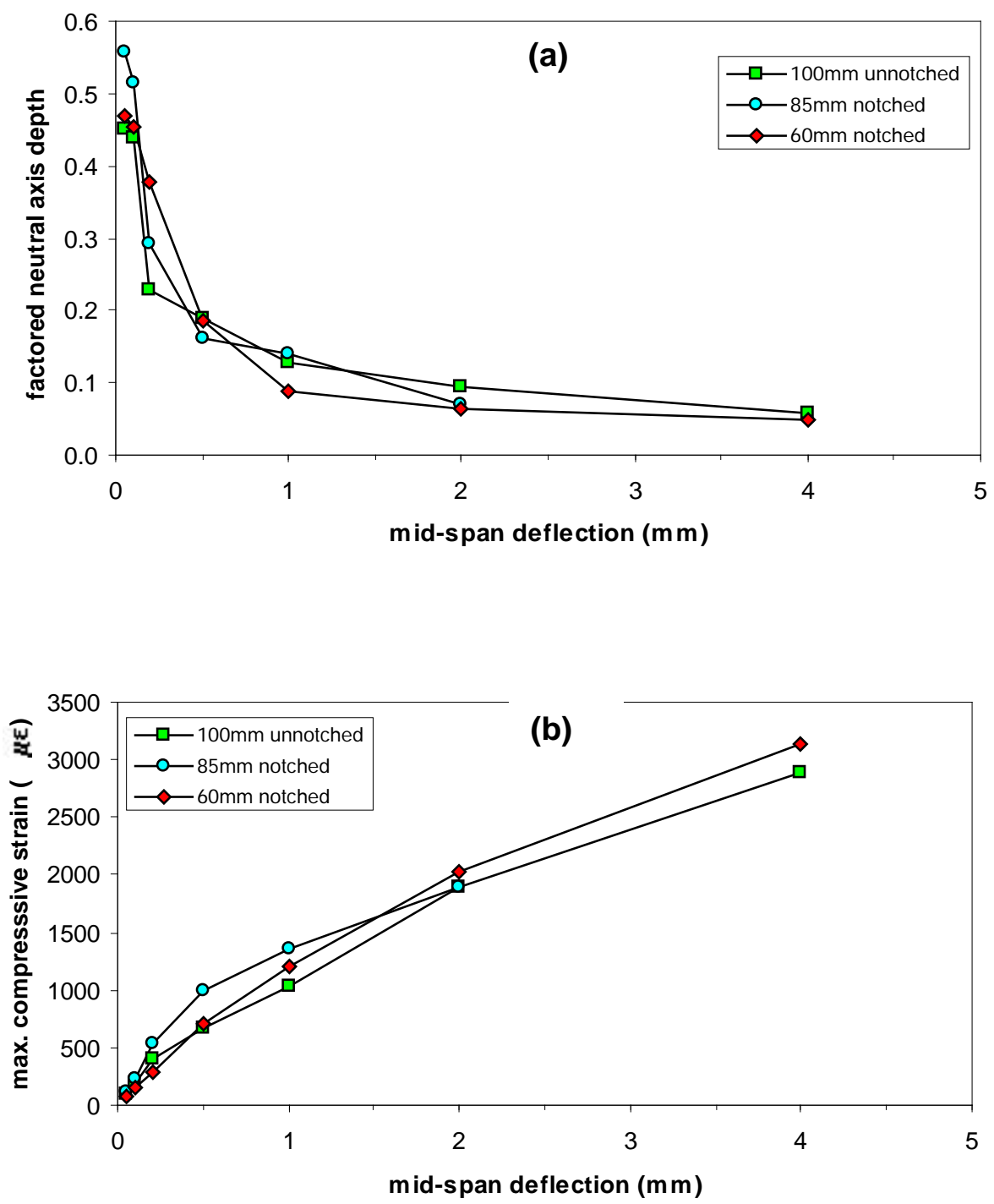

Figure 10 Relationship between (a) neutral axis depth and mid span deflection, and (b) strain measured at the compressive face of a beam and midspan deflection. 


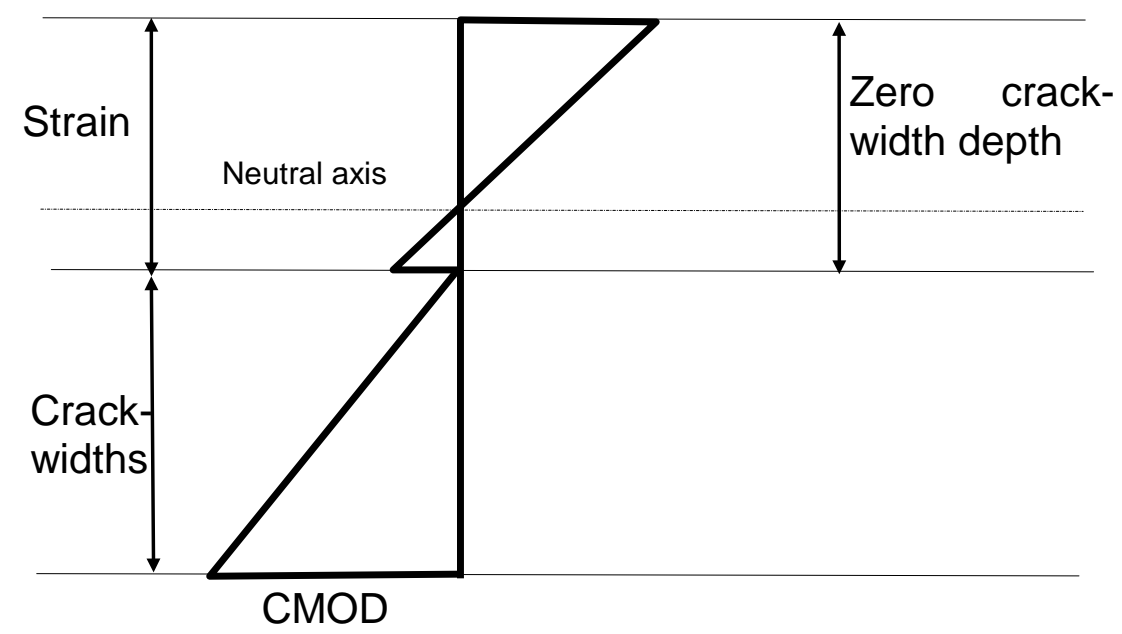

Figure $11 \quad$ Idealised strain/crack-width profile showing zero crack-width depth

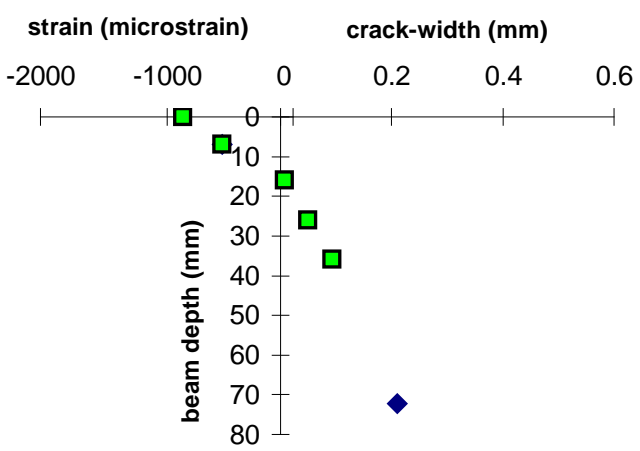

(a) $0.5 \mathrm{~mm}$

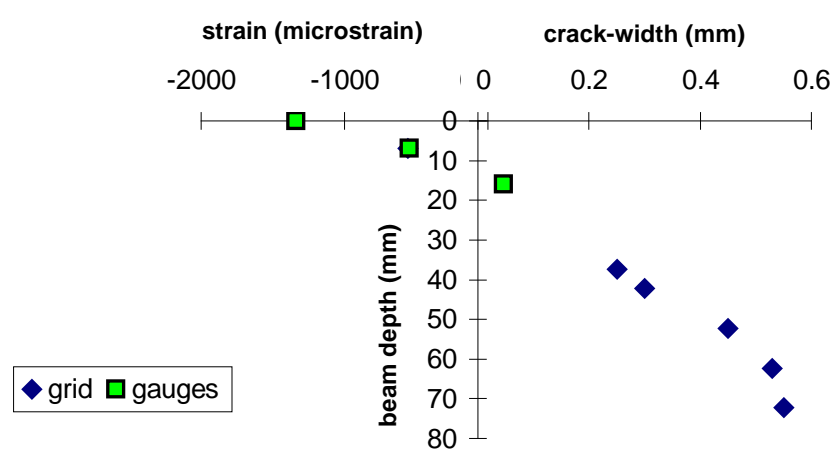

(b) $1.0 \mathrm{~mm}$

Figure 12 Strain and crack-width profiles from grid and strain gauge data 


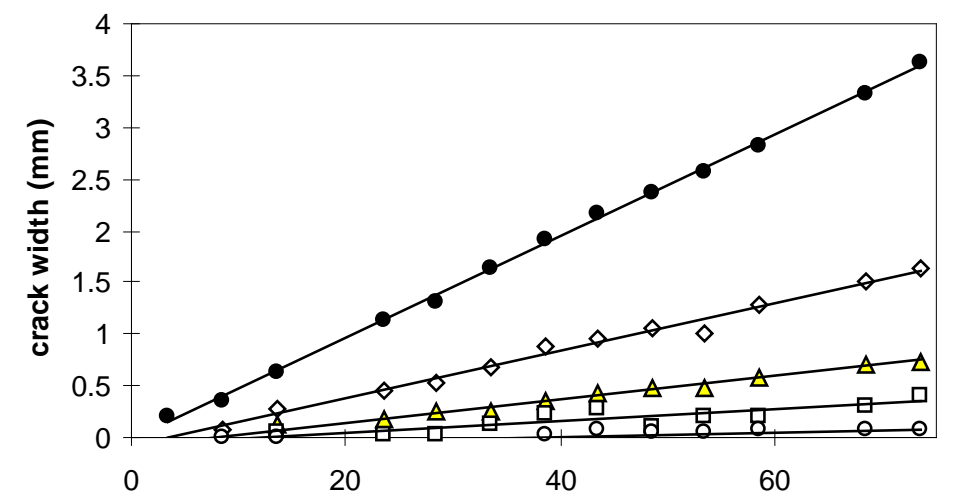

distance from compression face of beam $(\mathrm{mm})$

(a) $75 \mathrm{~mm}$ unnotched, $26 \mathrm{~kg} / \mathrm{m} 3$

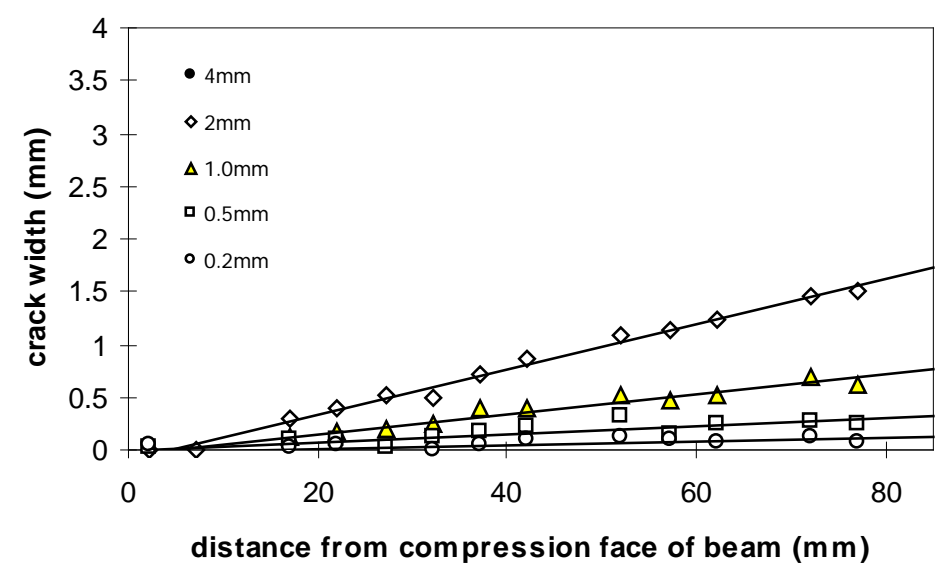

(c) $85 \mathrm{~mm}$ notched, $40 \mathrm{~kg} / \mathrm{m} 3$

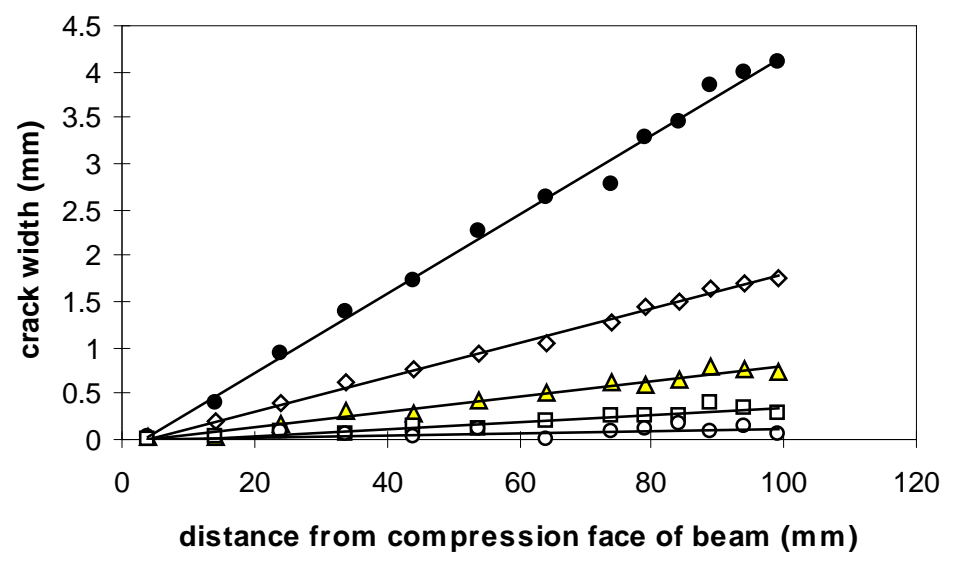

(b) $100 \mathrm{~mm}$ unnotched, $40 \mathrm{~kg} / \mathrm{m} 3$

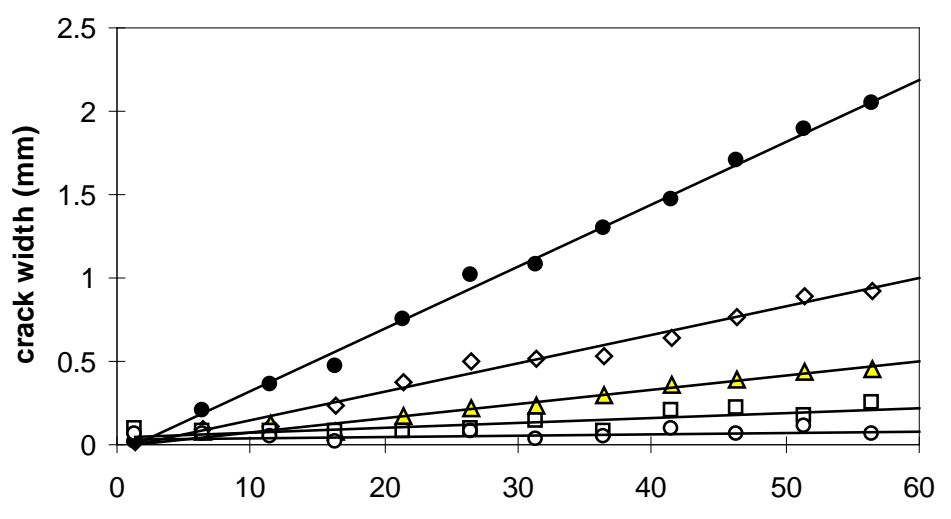

distance from compression face of beam $(\mathrm{mm})$

(d) $60 \mathrm{~mm}$ notched, $40 \mathrm{~kg} / \mathrm{m} 3$

Figure 4 Representative crack-width profiles from grid method analysis 
